\title{
openheart Sex differences in patients undergoing transcatheter aortic valve replacement in Asia
}

To cite: Chiam PTL,

Hayashida K, Watanabe Y, et al. Sex differences in patients undergoing transcatheter aortic valve replacement in Asia. Open Heart 2021;8:e001541.

doi:10.1136/

openhrt-2020-001541

Received 1 December 2020 Revised 12 December 2020 Accepted 14 December 2020
Check for updates

(C) Author(s) (or their employer(s)) 2021. Re-use permitted under CC BY-NC. No commercial re-use. See rights and permissions. Published by BMJ.

For numbered affiliations see end of article.

Correspondence to Dr Paul T L Chiam; paulchiam@ heartvascularcentre.com

\section{ABSTRACT}

Objectives Transcatheter aortic valve replacement (TAVR) is increasingly performed. Physically small Asians have smaller aortic root and peripheral vessel anatomy. The influence of gender of Asian patients undergoing TAVR is unknown and may affect outcomes. The aim of this study was to assess sex differences in Asian patients undergoing TAVR.

Methods Patients undergoing TAVR from eight countries were enrolled. In this retrospective analysis, we examined differences in characteristics, 30-day clinical outcomes and 1-year survival between female and male Asian patients.

Results Eight hundred and seventy-three patients (54.4\% women) were included. Women were older, smaller and had less coronary artery and lung disease but tended to have higher logistic EuroSCOREs. Smaller prostheses were used more often in women. Major vascular complications occurred more frequently in women $(5.5 \%$ vs $1.8 \%$, $\mathrm{p}<0.01$ ); however, 30-day stroke and mortality (women vs men: $1.5 \%$ vs $1.6 \%, p=0.95 \%$ and $4.3 \%$ vs $3.4 \%$, $\mathrm{p}=0.48$ ) were similar. Functional status improvement was significant and comparable between the sexes. Conduction disturbance and permanent pacemaker requirements ( $11.2 \%$ vs $9.0 \%, p=0.52)$ were also similar as was 1 -year survival (women vs men: $85.6 \%$ vs $88.2 \%, p=0.25$ ). The only predictors of 30-day mortality were major vascular injury in women and age in men.

Conclusions Asian women had significantly smaller stature and anatomy with some differences in clinical profiles. Despite more frequent major vascular complications, women had similar 30-day stroke or mortality rates. Functional status improvement was significant and comparable between the sexes. Conduction disturbance and permanent pacemaker requirements were similar as was 1 -year survival.

\section{INTRODUCTION}

Transcatheter aortic valve replacement (TAVR) has rapidly evolved to become an established treatment for patients with severe aortic valve stenosis who are inoperable or at

\section{Key questions}

What is already known about this subject?

- Although many studies have examined sex differences in transcatheter aortic valve replacement (TAVR) in Western countries, there are no data for sex differences in TAVR in Asia.

What does this study add?

- Despite the very small stature and more major vascular injury, Asian women have similar 30-day outcomes, functional status improvement, permanent pacemaker requirements and 1-year survival as Asian men, comparable with previously published studies on gender differences in TAVR.

How might this impact on clinical practice?

- Gender does not affect outcomes after TAVR in Asian patients and should not be a factor taken into consideration when assessing Asian patients for TAVR.

high surgical risk ${ }^{12}$ and an attractive alternative in intermediate-surgical-risk and lowsurgical-risk patients. ${ }^{3-6}$

TAVR was introduced in Asia in 2009, and the procedure has been increasingly performed in many centres and countries. There are now several reports demonstrating that women have outcomes comparable with men after TAVR in Western populations. ${ }^{8-16}$ However, data on the influence of gender on outcomes after TAVR in an Asian population are lacking, and there has only been a single report of a multicentre Asian registry. ${ }^{17}$ Asians are of smaller stature, and Asian women, in particular, have the smallest physique compared with other ethnic groups. It has been shown that Asians have smaller annulus and lower left coronary height than Caucasians, ${ }^{18}$ and Asian women have a significantly smaller iliofemoral anatomy than Asian 
men. ${ }^{19}$ Thus, the aims of this study were to assess the sex differences and outcomes of TAVR in Asian patients.

\section{METHODS}

Eight hundred and seventy-three patients undergoing TAVR from centres in eight countries across Northeast Asia and Southeast Asia were retrospectively included on all-comers basis in this observational registry. All centres underwent training and proctoring of the initial cases according to the manufacturers' protocols. Both highvolume and low-volume centres were eligible to participate.

All procedures were performed either with the balloonexpandable transcatheter heart valve (THV) or with the self-expanding THV. The balloon-expandable Edwards Sapien XT valve was delivered via the NovaFlex (18-19 French introducer sheaths) and then subsequently via the NovaFlex+ systems (16-18 French e-sheaths). Medtronic CoreValve prosthesis was delivered via the Accutrak (18French introducer sheath) system.

\section{Patient selection}

Patients were enrolled if they were inoperable for surgical aortic valve replacement or if they were deemed to be at high surgical risk. High surgical risk was defined as a logistic EuroSCORE $\geq 20 \%$ or a Society of Thoracic Surgeons Predicted Risk of Mortality $\geq 8 \%$ or a consensus opinion of two cardiothoracic surgeons/TAVR heart team.

\section{Valve sizing}

Early in the experience, echocardiography and angiography were the main imaging modalities used for valve sizing and for access site assessment. Subsequently, CT angiography became widely used and, where possible, was performed for nearly all cases of valve sizing and peripheral access measurements due to its superior spatial resolution.

\section{End points}

All end points were defined according to the Valve Academic Research Consortium -2 criteria. $^{20}$ They were site-reported, and there was no central adjudication. Baseline demographics, procedural parameters, in-hospital and 30-day outcomes and, where available, 1-year outcomes were recorded. The primary safety outcome was all-cause mortality at 30 days.

\section{Statistical analysis}

Continuous variables are presented as mean $\pm \mathrm{SD}$ and were compared between groups through the use of a twosample t-test. Categorical variables are given as frequencies and percentages and were compared by the $\chi^{2}$ test or Fisher's exact test. A value of $p<0.05$ was considered statistically significant.

The Kaplan-Meier survival analysis was used to estimate the unadjusted 1-year survival rate. Cox regression analysis was used to identify possible predictors of mortality.
The first step was selection of the variables using univariate analysis. Significant variables $(p \leq 0.1)$ were included in the multivariate model using stepwise Cox regression. Statistical significance remained the conventionally defined $\mathrm{p} \leq 0.05$ in the univariate and multivariate models. Statistical analyses were performed with SPSS V.20 (SPSS).

The study was investigator-led, and no industry funding was obtained. Each centre obtained local ethics committee approval for the study (including waiver of consent). There was no patient or public involvement in the study. The investigators take responsibility for the integrity of the data and have read and agree to the manuscript as written. We used the Strengthening the Reporting of Observational Studies in Epidemiology cohort checklist when writing our report.

\section{RESULTS \\ Demographics}

The mean age was $80 \pm 7.2$ years, and $54.4 \%$ were women, with women being older $(80.8 \pm 6.8$ years vs $78.9 \pm 7.5$ years, $\mathrm{p}<0.001$ ). The average female height was $149.4 \pm 7.0 \mathrm{~cm}$ (vs men $163.3 \pm 7.1 \mathrm{~cm}, \mathrm{p}<0.001$ ), and the corresponding body surface area (BSA) was $1.47 \pm 0.17 \mathrm{~m}^{2}$ versus $1.67 \pm 0.17 \mathrm{~m}^{2}$, respectively $(\mathrm{p}<0.001)$. Women had less comorbidities of smoking, coronary artery disease including percutaneous coronary intervention or bypass graft surgery, and lung disease (table 1). More women had prior valve surgery and tended to have a higher logistic EuroSCORE $(19.3 \pm 14.9$ vs $17.5 \pm 13.6, \mathrm{p}=0.07)$. The mean left ventricular ejection fraction (LVEF) was higher, and the annulus diameter was smaller in women (table 1).

\section{Procedural parameters}

Slightly more CoreValves $(52.7 \%)$ were used, less frequently in women compared with men $(44.2 \%$ vs $62.8 \%, \mathrm{p}<0.001)$. Conversely, the Sapien valve was used in 413 patients $(47.3 \%)$, more frequently in women compared with men $(55.8 \%$ vs $37.2 \%, \mathrm{p}<0.001)$. The transfemoral route was the access approach in $83.8 \%$ of women versus $88.2 \%$ of men $(\mathrm{p}=0.06)$. Valve sizes $\leq 23 \mathrm{~mm}$ were used more frequently in women $(51.4 \%$ vs $10.6 \%$, $\mathrm{p}<0.001)$, whereas valve sizes $\geq 29 \mathrm{~mm}$ were used less frequently in women $(11.0 \%$ vs $47.1 \%, \mathrm{p}<0.001)$. Procedural success was high and similar (women vs men: $98.3 \%$ vs $98.5 \%, \mathrm{p}=0.85$ ) in both sexes (table 2 ).

\section{Clinical outcomes}

Women experienced more major vascular complications $(5.5 \%$ vs $1.8 \%, \mathrm{p}=0.006)$ but had a lesser incidence of $\geq$ mild paravalvular leaks $(28.8 \%$ vs $35.9 \%, p=0.02)$, without any difference in the incidence of moderate/ severe paravalvular leaks $(2.7 \%$ vs $4.5 \%, \mathrm{p}=0.16)$ (table 3 ). Mean pressure gradients were similar (women vs men: $11.0 \pm 6.0 \mathrm{~mm} \mathrm{Hg}$ vs $10.6 \pm 5.7 \mathrm{~mm} \mathrm{Hg}, \mathrm{p}=0.40$ ); women had a smaller mean aortic valve area (AVA) $\left(1.6 \pm 0.4 \mathrm{~cm}^{2}\right.$ vs $\left.1.9 \pm 0.5 \mathrm{~cm}^{2}, \mathrm{p}<0.01\right)$, although there was no difference in the indexed AVA $(1.09 \pm 0.30$ vs $1.12 \pm 0.32, \mathrm{p}=0.33)$ 
Valvular heart disease

\begin{tabular}{|c|c|c|c|c|}
\hline & All $(n=873)$ & Male $(n=398)$ & Female $(n=475)$ & $P$ value \\
\hline Age, mean (SD), years & $80.0(7.2)$ & $78.9(7.5)$ & $80.8(6.8)$ & $<0.001$ \\
\hline Weight, mean (SD), kg & $56.7(12.3)$ & $62.2(11.5)$ & $52.3(11.0)$ & $<0.001$ \\
\hline Height, mean (SD), cm & 155.7 (9.8) & $163.3(7.1)$ & $149.4(7.0)$ & $<0.001$ \\
\hline BSA, mean (SD) & $1.56(0.20)$ & $1.67(0.17)$ & $1.47(0.17)$ & $<0.001$ \\
\hline BMI, mean (SD) & $23.4(4.1)$ & $23.3(3.8)$ & $23.4(4.4)$ & 0.74 \\
\hline Logistic EuroSCORE (SD) & $18.5(14.4)$ & $17.5(13.6)$ & $19.3(14.9)$ & 0.07 \\
\hline $\mathrm{DM}, \mathrm{n}(\%)$ & $274(31.4)$ & $125(31.4)$ & $149(31.4)$ & 0.97 \\
\hline HPT, n (\%) & $663(75.9)$ & $305(76.6)$ & $358(75.4)$ & 0.74 \\
\hline Lipids, n (\%) & 475 (54.4) & 218 (54.8) & $257(54.1)$ & 0.67 \\
\hline Smoker, n (\%) & $150(17.2)$ & $129(32.4)$ & $21(4.4)$ & $<0.001$ \\
\hline IHD & $449(51.4)$ & $228(57.3)$ & $221(46.5)$ & 0.002 \\
\hline Prior PCl, n (\%) & 301 (34.5) & $157(39.4)$ & $144(30.3)$ & 0.005 \\
\hline Prior CABG, n (\%) & $111(12.7)$ & $68(17.1)$ & $43(9.1)$ & $<0.001$ \\
\hline Carotid artery stenosis $>50 \%, \mathrm{n}(\%)$ & $72(8.2)$ & $33(8.3)$ & $39(8.2)$ & 0.86 \\
\hline Peripheral vascular disease, $\mathrm{n}(\%)$ & $158(18.1)$ & 78 (19.6) & $80(16.8)$ & 0.24 \\
\hline Prior valve replacement, $\mathrm{n}(\%)$ & $25(2.9)$ & $3(0.8)$ & $22(4.6)$ & $<0.001$ \\
\hline NYHA class, mean & $2.8(0.7)$ & $2.8(0.7)$ & $2.8(0.7)$ & 0.25 \\
\hline NYHA class III or IV, n (\%) & $580(66.4)$ & $259(65.1)$ & $321(67.6)$ & 0.35 \\
\hline $\mathrm{EF}, \%$ (SD) & $58(13)$ & $55(14)$ & $59(13)$ & $<0.001$ \\
\hline AVA, mean (SD), cm2 & $0.66(0.19)$ & $0.70(0.18)$ & $0.63(0.19)$ & $<0.001$ \\
\hline Indexed AVA, mean (SD), $\mathrm{cm}^{2} / \mathrm{m}^{2}$ & $0.43(0.12)$ & $0.42(0.11)$ & $0.43(0.13)$ & 0.07 \\
\hline MPG, mean (SD), mm Hg & $50.9(18.8)$ & $51.0(18.5)$ & $50.8(19.0)$ & 0.87 \\
\hline Annulus, mean (SD), mm & $22.3(3.1)$ & $23.8(3.6)$ & $21.0(1.9)$ & $<0.001$ \\
\hline AR > grade $2, n(\%)$ & $152(17.4)$ & 66 (16.6) & $86(18.1)$ & 0.29 \\
\hline MR > grade $2, n(\%)$ & $116(13.3)$ & $58(14.6)$ & $58(12.2)$ & 0.69 \\
\hline Renal disease, $\mathrm{n}(\%)$ & $53(6.1)$ & $26(6.5)$ & $27(5.7)$ & 0.74 \\
\hline Lung disease, $\mathrm{n}(\%)$ & $37(4.2)$ & $25(6.3)$ & $12(2.5)$ & 0.02 \\
\hline Calcified aorta, n (\%) & $44(5.0)$ & $18(4.5)$ & $26(5.5)$ & 0.25 \\
\hline Pulmonary hypertension, $\mathrm{n}(\%)$ & $9(1.0)$ & $5(1.3)$ & $4(0.8)$ & 0.69 \\
\hline Previous CVA, n (\%) & $6(0.7)$ & $2(0.5)$ & $4(0.8)$ & 0.68 \\
\hline Minimal femoral diameter, mean (SD), mm* & $7(1.7)$ & $7.3(1.8)$ & $6.3(1.5)$ & $<0.001$ \\
\hline
\end{tabular}

*Data taken from Chiam et $\mathrm{al}^{19}$ in a cohort of Asian patients with similar physical stature.

AR, aortic regurgitation; AVA, aortic valve area ; BMI, body mass index; BSA, body surface area; CABG, coronary artery bypass grafting; CVA, cerebrovascular accident; DM, diabetes mellitus; EF, ejection fraction; HPT, hypertension; IHD, ischaemic heart disease; MPG, mean pressure gradient; MR, mitral regurgitation; NYHA, New York Heart Association; PCl, percutaneous coronary intervention.

(table 3). Both sexes derived comparable symptomatic benefit with a 30-day mean New York Heart Association (NYHA) class of $1.5 \pm 0.6$ (from NYHA class $2.8 \pm 0.7$ ), with only $5.7 \%$ of women and $4.8 \%$ of men remaining in NYHA class III or IV $(\mathrm{p}=0.82)$. There was no difference in the incidence of new left bundle branch block (women vs men: $14.5 \%$ vs $14.7 \%, \mathrm{p}=0.99$ ) or permanent pacemaker requirement (overall 9.4\%; women vs men: $11.2 \%$ vs $9.0 \%, \mathrm{p}=0.52)$.

The 30-day mortality was $3.8 \%$, with no difference between women and men $(4.3 \%$ vs $3.4 \%, \mathrm{p}=0.48)$. The 30-day stroke rate was also similar (women vs men: $1.5 \%$ vs $1.6 \%, \mathrm{p}=0.95$ ). Survival at 1 year was $85.6 \%$ in women and $88.2 \%$ in men $(p=0.25)$ (figure 1$)$.
On multivariable analyses, predictors of major vascular injury were age (OR 1.08, 95\% CI 1.02 to $1.16, \mathrm{p}=0.011$ ) and female sex (OR 2.81, 95\% CI 1.02 to 7.74, $\mathrm{p}=0.046$ ), whereas BSA or body mass index (BMI) was not associated.

Predictors of 30-day mortality were age (OR 0.93, $95 \%$ CI 0.88 to $0.99, p=0.016$ ) and major vascular injury (OR 11.66, 95\% CI 3.28 to 41.41, $\mathrm{p}<0.001$ ) for the entire cohort-major vascular injury only for women (OR $21.70,95 \%$ CI 4.17 to $112.79, \mathrm{p}<0.001$ ) and age only for men (OR $0.87,95 \%$ CI 0.80 to $0.95, p=0.002)$. Predictors of 1-year mortality were logistic EuroSCORE (OR 1.05, $95 \%$ CI 1.02 to $1.08, \mathrm{p}=0.004$ ), hypertension (OR 20.65, $95 \%$ CI 2.21 to $192.64, \mathrm{p}=0.008$ ), moderate or more paravalvular leak (OR 43.52, 95\% CI 5.38 to $352.07, \mathrm{p}<0.001$ ) 


\begin{tabular}{|c|c|c|c|c|}
\hline & All $(n=873)$ & Male $(n=398)$ & Female $(n=475)$ & $P$ value \\
\hline CoreValve, n (\%) & $460(52.7)$ & $250(62.8)$ & $210(44.2)$ & $<0.001$ \\
\hline Sapien XT, n (\%) & $413(47.3)$ & $148(37.2)$ & $265(55.8)$ & $<0.001$ \\
\hline \multicolumn{5}{|l|}{ Valve size, $\mathrm{n}(\%), \mathrm{mm}$} \\
\hline 20 & $3(0.3)$ & $0(0)$ & $3(0.6)$ & 0.26 \\
\hline 23 & $283(32.4)$ & $42(10.6)$ & $241(50.8)$ & $<0.001$ \\
\hline 26 & $346(39.6)$ & $168(42.3)$ & $178(37.6)$ & 0.15 \\
\hline 29 & $188(21.5)$ & $141(35.5)$ & $47(9.9)$ & $<0.001$ \\
\hline 31 & $51(5.8)$ & $46(11.6)$ & $5(1.1)$ & $<0.001$ \\
\hline Transfemoral, n (\%) & $749(85.8)$ & 351 (88.2) & $398(83.8)$ & 0.06 \\
\hline Second valve, $\mathrm{n}(\%)$ & $9(1.0)$ & $7(1.9)$ & $2(0.4)$ & 0.16 \\
\hline Procedural success, $n(\%)$ & $122(98.4)$ & $392(98.5)$ & $467(98.3)$ & 0.85 \\
\hline
\end{tabular}

and 30-day NYHA class III or IV (OR 8.90, 95\% CI 1.82 to 43.64, $\mathrm{p}=0.007$ ) for the entire cohort; no separate analysis stratified by sex was performed due to the low end point count.

\section{DISCUSSION}

Transcatheter aortic valve replacement (TAVR) is increasingly performed in Asia after a relatively late start. $^{21}$ Several studies have now examined TAVR in an Asian population, ${ }^{1722}$ with the majority of data from the Japanese Optimised transCathEter vAlvular iNtervention (OCEAN)-TAVR registry, which is specific, however, to one Asian ethnic group and to the balloon-expandable device. Data comparing gender differences in a broad geography of Asia and across various Asian ethnicities are lacking. Our study is the first description of sex-related differences in patients undergoing TAVR across Asia and across the various Asian ethnic groups.

An interesting and unique finding was the very small physical stature (eg, average height $\approx 149 \mathrm{~cm}$ ) in elderly female Asians. Female patients had better LVEF and less comorbidities with respect to coronary artery disease, smoking and chronic lung disease, but were older and more likely to have had prior heart valve surgery, resulting in a trend towards a higher logistic EuroSCORE. With the smaller physical stature, smaller aortic annulus and, as shown in a previous study, smaller iliofemoral dimensions, ${ }^{19}$ the transfemoral route was used slightly less frequently, and the prostheses used in women were also smaller in size. However, mild or more paravalvular leak was also less frequent in women.

Despite more serious vascular complications occurring in female patients, the 30-day rates of stroke or mortality were low and similar between the sexes. Of note, most, if not all, centres were beginning their TAVR programmes, and most of the valves used were second-generation balloon-expandable or self-expanding valves. Functional status improved significantly and uniformly for both sexes; NYHA class III or IV at baseline was $67.5 \%$ in women versus $65.3 \%$ in men $(p=0.35)$ to $5.7 \%$ in women and $4.8 \%$ in men at 30 days $(p=0.92)$. At

Table 3 Thirty-day clinical outcomes

\begin{tabular}{|c|c|c|c|c|}
\hline & All $(n=873)$ & Male $(n=398)$ & Female $(n=475)$ & $P$ value \\
\hline Death, $\mathrm{n}(\%)$ & $33(3.8)$ & $13(3.4)$ & $20(4.3)$ & 0.48 \\
\hline Stroke, n (\%) & $13(1.5)$ & $6(1.6)$ & $7(1.5)$ & 0.95 \\
\hline Major vascular injury, $\mathrm{n}(\%)$ & $32(3.7)$ & $7(1.8)$ & $25(5.5)$ & 0.006 \\
\hline NYHA class, mean & $1.5(0.6)$ & $1.5(0.6)$ & $1.5(0.6)$ & 0.88 \\
\hline NYHA class III or IV, n (\%) & $36(4.1)$ & $16(4.8)$ & $20(5.7)$ & 0.82 \\
\hline$E F, \%$ (SD) & $59(11)$ & $58(12)$ & $61(11)$ & 0.02 \\
\hline AVA, mean (SD), cm2 & $1.7(0.5)$ & $1.9(0.5)$ & $1.6(0.4)$ & $<0.001$ \\
\hline Indexed AVA, mean (SD), $\mathrm{cm}^{2} / \mathrm{m}^{2}$ & $1.10(0.31)$ & $1.12(0.32)$ & $1.09(0.30)$ & 0.33 \\
\hline MPG, mm Hg (SD) & $10.8(5.9)$ & $10.6(5.7)$ & $11.0(6.0)$ & 0.40 \\
\hline Paravalvular leak (mild or more), n (\%) & $280(32.1)$ & $143(35.9)$ & $137(28.8)$ & 0.02 \\
\hline Paravalvular leak (moderate-severe), n (\%) & $31(3.6)$ & $18(4.5)$ & $13(2.7)$ & 0.16 \\
\hline New LBBB, n (\%) & $116(13.3)$ & $51(14.7)$ & 65 (14.5) & 0.99 \\
\hline PPM, n (\%) & $82(9.4)$ & $33(9.0)$ & 49 (11.2) & 0.52 \\
\hline
\end{tabular}

AVA, aortic valve area; EF, ejection fraction; LBBB, left bundle branch block; MPG, mean pressure gradient; NYHA, New York Heart Association; PPM, permanent pacemaker. 


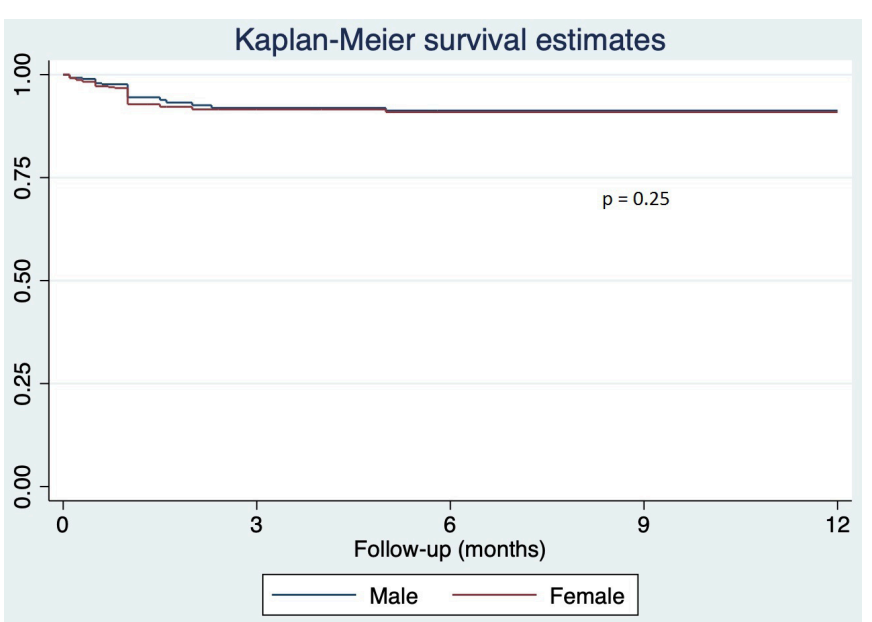

Figure 1 One-year Kaplan-Meier survival curves of women versus men.

1 year, there was no difference in survival between the sexes, despite women being older and having a trend towards a higher baseline EuroSCORE. The 1-year mortality somewhat approximated the baseline logistic EuroSCORE and is concordant with the findings from a previous Asian registry. ${ }^{17}$

Our data are consistent with several studies showing no differencein 30-day or 1-year survival between the sexes despite a higher incidence of major vascular complications, ${ }^{811-132425}$ although some studies demonstrate that women have a better 1-year or long-term survival after TAVR. ${ }^{1011} 1416$ Although we did not record the iliofemoral dimensions in this study, it has been shown in a previous study by the first author that Asian women had significantly smaller iliofemoral dimensions than Asian men. ${ }^{19}$ In that study, the minimal femoral diameters were $6.3 \pm 1.5 \mathrm{~mm}$ versus $7.3 \pm 1.8 \mathrm{~mm}$ in women and men, respectively $(p<0.001)$. The BSA of both sexes in that study was nearly identical with the current results (women vs men: $1.5 \pm 0.2 \mathrm{vs} 1.7 \pm 0.2, \mathrm{p}<0.001$ in the previous study compared with $1.47 \pm 1.7$ vs $1.67 \pm 1.7, \mathrm{p}<0.001$ in this study), indicating that the physical stature of the study populations was similar. As there was no difference in the incidence of peripheral artery disease between the sexes and interestingly because BSA or BMI was not associated with major vascular injury, the higher rate of major vascular complications in women in our study may be attributed to smaller ilio-femoral dimensions, older age and female sex itself (both of these may arguably be markers of vessel fragility).

More importantly, our study demonstrated that TAVR could achieve an equally good outcome for Asian women despite their smaller size and anatomy and higher incidence of major vascular complications. In contrast, it has been shown in some studies that a smaller height and female sex may be correlated with increased mortality after surgical $\mathrm{TAVR}^{25-27}$; thus, it is reassuring that physically small Asian women do not experience increased short-term mortality after TAVR. In concordance with Western data, women had less comorbidities associated with coronary artery disease and lung disease, ${ }^{8-1113}$ and these could be accounted for by a much lower incidence of smoking. Women also had less mild or more paravalvular leaks, consistent with some studies ${ }^{911} 122425$ but not others. ${ }^{10}$ It has been suggested that this is possibly due to the smaller aortic annulus in women leading to less frequently undersized prosthesis and more relative valve oversizing. It is reassuring, however, to note that the incidence of permanent pacemaker replacement was not increased in women.

It was interesting to note that although age and major vascular injury predicted overall 30-day mortality, only major vascular injury was significant for women and only age was significant for men. This implies that it is imperative to reduce major vascular injury in women to decrease shortterm mortality.

The factors associated with 1-year mortality in this study-logistic EuroSCORE, hypertension, moderate or more paravalvular leak, 30-day NYHA class III or IVreaffirm what is already well understood and are broadly consistent with a previous Asian registry. ${ }^{17}$

With the third-generation balloon-expandable (Sapien 3) valve and self-expanding (Evolut $R$ and Pro) valves becoming commercially available in Asia in the recent years, the outcomes can be expected to improve. In particular, residual paravalvular leaks (both severity and frequency) for both sexes should be lowered, and the incidence of major vascular complications, especially in women, can be expected to be reduced.

\section{Limitations}

This study was limited to centres that agreed to participate, and hence data from many institutions in Asia were not available. These factors may have introduced bias into the study population. The data and outcomes were recorded by the individual centres, and no central adjudication was available. The data were analysed retrospectively and the possibility of unmeasured confounders that may have affected our results could not be excluded. There were missing parameters such as femoral/iliac vessel dimensions (CT measurements were unavailable or incomplete in many centres).

No information was available regarding the types of anaesthesia used (general anaesthesia vs local anaesthesia/ conscious sedation) or the technique of femoral access (surgical cut-down versus fluoroscopy-guided percutaneous access). However, studies have shown that the incidence of major vascular injury was similar regardless of the access technique. ${ }^{28}{ }^{29}$ The devices used in this study were secondgeneration Sapien or CoreValve prostheses; thus, these results may not apply to other devices or new-generation contemporary technologies.

\section{CONCLUSIONS}

This is the first study examining sex differences in TAVR in patients across Asia and across multiple Asian ethnicities. Women had significantly smaller physical stature and anatomy with some differences in clinical profiles. Despite a higher rate of major vascular complications, Asian women had similar 30-day stroke or death rates, functional status improvement, permanent pacemaker requirements and 1-year survival as men. 
Author affiliations

${ }^{1}$ The Heart and Vascular Centre, Mount Elizabeth Medical Centre, Singapore

${ }^{2}$ Department of Cardiology, Keio University School of Medicine, Tokyo, Japan

${ }^{3}$ Department of Cardiology, Teikyo University Hospital, Tokyo, Japan

${ }^{4}$ Division of Cardiology, Heart Center, Cheng-Hsin General Hospital, Taipei, Taiwan

${ }^{5}$ Internal Medicine, National Taiwan University Hospital, Taipei, Taiwan

${ }^{6}$ Department of Cardiology, Queen Elizabeth Hospital, Hong Kong, Hong Kong

${ }^{7}$ Department of Cardiology, St. Luke's Medical Centre, Manila, Philippines

${ }^{8}$ Division of Cardiology, Ramathibodi Hospital, Bangkok, Thailand

${ }^{9}$ Medicine, Chulalongkorn University, Bangkok, Thailand

${ }^{10}$ Heart Institute, Chinese General Hospital and Medical Centre, Manila, Philippines

${ }^{11}$ Department of Cardiology, Vietnam National Heart Institute, Hanoi, Vietnam

${ }^{12}$ Department of Cardiology, CHA Bundang Medical Centre, Seoul, Republic of Korea

${ }^{13}$ Cardiology, The Catholic University of Korea Seoul St. Mary's Hospital, Seoul,

Republic of Korea

${ }^{14}$ Department of Internal Medicine, National Taiwan University Hospital, Taipei, Taiwan

${ }^{15}$ Hong Kong Asia Heart Centre, Canossa Hospital, Hong Kong, Hong Kong

${ }^{16}$ Department of Cardiology, National Heart Institute, Kuala Lumpur, Malaysia

${ }^{17}$ Department of Cardiology, National Heart Centre Singapore, Singapore

${ }^{18}$ Department of Cardiology, Zhongshan Hospital, Fudan University, Shanghai, China

${ }^{19}$ Department of Cardiology, The Second Affiliated Hospital, Zhejiang University

School of Medicine, Hangzhou, China

${ }^{20}$ Cardiology, Second Affiliated Hospital, Zhejiang University School of Medicine, Hangzhou, China

${ }^{21}$ Department of Internal Medicine, Seoul National University Hospital, Seoul, Republic of Korea

${ }^{22}$ Department of Cardiology, Sichuan University West China Hospital, Chengdu, China

Contributors PTLC conceived the study, interpreted the data and wrote the manuscript. NQN performed the statistical analyses and reviewed the manuscript. All other authors helped to critically revise the manuscript and approved the final manuscript. PTLC takes responsibility for the overall content as a guarantor.

Funding The authors have not declared a specific grant for this research from any funding agency in the public, commercial or not-for-profit sectors.

Competing interests PTLC, KH, YW, W-HY, MKYL, MC, WJK, KC, M-SL and HSK have served as proctors for Edwards Lifesciences. PTLC, YW, W-HY, H-LK, MKYL, WB, Dy, KC, M-SL, KWH and HSK have served as proctors for Medtronic. WJK has served as a consultant for Medtronic.

Patient consent for publication Not required.

Provenance and peer review Not commissioned; internally peer reviewed.

Data availability statement All data relevant to the study are included in the article or uploaded as supplementary information. All data are deidentified and stored in a secure stand-alone computer.

Open access This is an open access article distributed in accordance with the Creative Commons Attribution Non Commercial (CC BY-NC 4.0) license, which permits others to distribute, remix, adapt, build upon this work non-commercially, and license their derivative works on different terms, provided the original work is properly cited, appropriate credit is given, any changes made indicated, and the use is non-commercial. See: http://creativecommons.org/licenses/by-nc/4.0/.

ORCID iDs

Paul T L Chiam http://orcid.org/0000-0002-1901-757X

Mao-Shin Lin http://orcid.org/0000-0003-3278-4156

Jian'an Wang http://orcid.org/0000-0002-4583-3204

\section{REFERENCES}

1 Leon MB, Smith CR, Mack M, et al. Transcatheter aortic-valve implantation for aortic stenosis in patients who cannot undergo surgery. N Engl J Med 2010;363:1597-607.

2 Smith CR, Leon MB, Mack MJ, et al. Transcatheter versus surgical aortic-valve replacement in high-risk patients. $N$ Engl J Med 2011;364:2187-98.

3 Leon MB, Smith CR, Mack MJ, et al. Transcatheter or surgical aortic-valve replacement in intermediate-risk patients. $N$ Engl J Med 2016;374:1609-20.
4 Reardon MJ, Van Mieghem NM, Popma JJ, et al. Surgical or transcatheter aortic-valve replacement in intermediate-risk patients. N Engl J Med 2017;376:1321-31.

5 Mack MJ, Leon MB, Thourani VH, et al. Transcatheter aortic-valve replacement with a Balloon-Expandable valve in low-risk patients. $N$ Engl J Med 2019;380:1695-705.

6 Popma JJ, Deeb GM, Yakubov SJ, et al. Transcatheter aortic-valve replacement with a self-expanding valve in low-risk patients. $N$ Engl $J$ Med 2019;380:1706-15.

7 Chiam PT, Koh TH, Chao VT, et al. Percutaneous transcatheter aortic valve replacement: first transfemoral implant in Asia. Singapore Med J 2009;50:534-7.

8 Vlastra W, Chandrasekhar J, García Del Blanco B, et al. Sex differences in transfemoral transcatheter aortic valve replacement. $J$ Am Coll Cardiol 2019;74:2758-67.

9 Katz M, Carlos Bacelar Nunes Filho A, Caixeta A, et al. Genderrelated differences on short- and long-term outcomes of patients undergoing transcatheter aortic valve implantation. Catheter Cardiovasc Interv 2017:89:429-36.

10 Chandrasekhar J, Dangas G, Yu J, et al. Sex-based differences in outcomes with transcatheter aortic valve therapy: TVT registry from 2011 to 2014. J Am Coll Cardiol 2016;68:2733-44.

11 O'Connor SA, Morice M-C, Gilard M, et al. Revisiting sex equality with transcatheter aortic valve replacement outcomes: a collaborative, patient-level meta-analysis of 11,310 patients. J Am Coll Cardiol 2015;66:221-8.

12 Al-Lamee R, Broyd C, Parker J, et al. Influence of gender on clinical outcomes following transcatheter aortic valve implantation from the UK transcatheter aortic valve implantation registry and the National Institute for cardiovascular outcomes research. Am J Cardiol 2014;113:522-8.

13 D'Ascenzo F, Gonella A, Moretti C, et al. Gender differences in patients undergoing TAVI: a multicentre study. Eurolntervention 2013;9:367-72

14 Hayashida K, Morice M-C, Chevalier B, et al. Sex-related differences in clinical presentation and outcome of transcatheter aortic valve implantation for severe aortic stenosis. J Am Coll Cardiol 2012;59:566-71.

15 Conrotto F, D'Ascenzo F, Salizzoni S, et al. A gender based analysis of predictors of all cause death after transcatheter aortic valve implantation. Am J Cardiol 2014;114:1269-74.

16 Humphries KH, Toggweiler S, Rodés-Cabau J, et al. Sex differences in mortality after transcatheter aortic valve replacement for severe aortic stenosis. J Am Coll Cardiol 2012;60:882-6.

17 Yoon S-H, Ahn J-M, Hayashida K, et al. Clinical outcomes following transcatheter aortic valve replacement in asian population. JACC Cardiovasc Interv 2016;9:926-33.

18 Yoon S-H, Ohno Y, Araki M, et al. Comparison of aortic root anatomy and calcification distribution between Asian and Caucasian patients who underwent transcatheter aortic valve implantation. Am J Cardiol 2015;116:1566-73.

19 Chiam PTL, Koh AS, Ewe SH, et al. Iliofemoral anatomy among Asians: implications for transcatheter aortic valve implantation. Int $J$ Cardiol 2013;167:1373-9.

20 Kappetein AP, Head SJ, Généreux P, et al. Updated standardized endpoint definitions for transcatheter aortic valve implantation: the valve academic research Consortium-2 consensus document. Eur Heart J 2012;33:2403-18

21 Chiam PTL. Transcatheter aortic valve implantation in Asia: the first decade. Eurolntervention 2018;14:35-7.

22 Miyasaka M, Tada N, Taguri M, et al. Incidence, predictors, and clinical impact of Prosthesis-Patient mismatch following transcatheter aortic valve replacement in Asian patients: the OCEAN-TAVI registry. JACC Cardiovasc Interv 2018;11:771-80.

23 Hosoba S, Yamamoto M, Shioda K, et al. Safety and efficacy of minimalist approach in transfemoral transcatheter aortic valve replacement: insights from the optimized transcatheter vAlvular interventioN-Transcatheter aortic valve implantation (OCEAN-TAVI) registry. Interact Cardiovasc Thorac Surg 2018;26:420-4.

24 Conrotto F, D'Ascenzo F, Presbitero P, et al. Effect of gender after transcatheter aortic valve implantation: a meta-analysis. Ann Thorac Surg 2015;99:809-16.

25 Onorati F, D'Errigo P, Barbanti M, et al. Different impact of sex on baseline characteristics and major periprocedural outcomes of transcatheter and surgical aortic valve interventions: results of the multicenter Italian OBSERVANT registry. J Thorac Cardiovasc Surg 2014:147:1529-39.

26 Florath I, Rosendahl UP, Mortasawi A, et al. Current determinants of operative mortality in 1400 patients requiring aortic valve replacement. Ann Thorac Surg 2003;76:75-83. 
27 Parikh PB, Wang T-Y, Sharma N, et al. Sex-related differences in early- and long-term mortality after transcatheter and surgical aortic valve replacement: a systematic review and meta-analysis. J Invasive Cardiol 2020;32:295-301.

28 Nakamura M, Chakravarty T, Jilaihawi $\mathrm{H}$, et al. Complete percutaneous approach for arterial access in transfemoral transcatheter aortic valve replacement: a comparison with surgical cut-down and closure. Catheter Cardiovasc Interv 2014;84:293-300.

29 Drafts BC, Choi $\mathrm{CH}$, Sangal K, et al. Comparison of outcomes with surgical cut-down versus percutaneous transfemoral transcatheter aortic valve replacement: TAVR transfemoral access comparisons between surgical cut-down and percutaneous approach. Catheter Cardiovasc Interv 2018:91:1354-62. 